\title{
EFSUMB Clinical Safety Statement for Diagnostic Ultrasound - (2019 revision)
}

\section{EFSUMB-Statement über die klinische Sicherheit der Ultraschalldiagnostik - (2019 Revision)}

Authors

Christian Kollmann¹, Klaus-Vitold Jenderka², Carmel M. Moran ${ }^{3}$, Ferdinando Draghi ${ }^{4}$, J. F. Jimenez Diaz ${ }^{5,6}$, Ragnar Sande ${ }^{7,8}$

Affiliations

1 Center for Medical Physics \& Biomedical Engineering, Medical University Vienna, Austria

2 Department of Engineering and Natural Sciences, University of Applied Sciences, Merseburg, Germany

3 University-BHF Centre for Cardiovascular Science, Edinburgh-University, Edinburgh, United Kingdom of Great Britain and Northern Ireland

4 Institute of Radiology, University of Pavia, IRCCSFoundation, San Matteo Medical Center, Pavia, Italy

5 Castilla La Mancha University Education Faculty of Toledo Sport Sciences Faculty Toledo, Castilla La Mancha, Spain

6 UCAM - Sport Medicine Department Murcia, Murcia, Spain

7 Stavanger University Hospital - Department of obstetrics and gynecology, Stavanger, Norway

8 University of Bergen - Department of clinical science, Bergen, Hordaland, Norway

Key words

ultrasound, safety, recommendation

received 04.07.2019

accepted 20.08.2019

Bibliography

DOI https://doi.org/10.1055/a-1010-6018

Published online: October 8, 2019

Ultraschall in Med 2020; 41: 387-389

(c) Georg Thieme Verlag KG, Stuttgart · New York

ISSN 0172-4614
Correspondence

Prof. Christian Kollmann

Center for Medical Physics \& Biomedical Engineering, Medical University Vienna, Waehringer Gürtel 18-20, AKH Wien E 4L, 1090 Vienna, Austria

Tel.: ++43/1/40 40073730

Fax: $++43 / 1 / 404003988$

christian.kollmann@meduniwien.ac.at

\section{ABSTRACT}

This document is the updated 2019 revision of the EFSUMB Clinically Safety Statement. A Safety Statement has been published by EFSUMB annually since 1994 by the Safety Committee (ECMUS) of the federation. The text is deliberately brief and gives a concise overview of safety in the use of diagnostic ultrasound.

\section{ZUSAMMENFASSUNG}

Dieses Dokument ist die 2019 aktualisierte Revision des EFSUMB-Clinically-Safety-Statements. Diese Stellungnahme zur Sicherheit wird von der EFSUMB seit 1994 jährlich durch das Sicherheitskomitee (ECMUS) der EFSUMB veröffentlicht. Der Text ist bewusst kurz gehalten und gibt einen prägnanten Überblick über die Sicherheit bei Anwendung des diagnostischen Ultraschalls.

\section{General Information}

Diagnostic ultrasound has been widely used in clinical medicine for many years with no proven deleterious effects. Biological effects (such as localized pulmonary capillary bleeding) have been reported in mammalian systems at diagnostically relevant exposures, but the clinical significance of such effects is not fully known [1]. Consequently, diagnostic ultrasound can be considered safe only if used prudently.
Ultrasound examinations should be performed only by competent personnel who are trained and updated on safety matters.

It is important that ultrasound devices are CE- (European Conformity) approved and appropriately maintained. The range of clinical applications is becoming wider, the number of patients undergoing ultrasound examinations is increasing and new techniques with higher acoustic output levels and new pulse emission sequences are being introduced. It is therefore essential to maintain vigilance to ensure the continued safe use of ultrasound. 


\section{Available safety information during clinical scanning}

Ultrasound produces heating, pressure changes and mechanical disturbances in tissue. Diagnostic levels of ultrasound are capable of producing temperature rises that may be hazardous to sensitive organs and the embryo/fetus. Biological effects of nonthermal origin have been reported in animals [2], but to date, no such effects have been demonstrated in humans, except when a microbubble contrast agent is present.

\section{The ALARA-Principle}

The Thermal Index (TI) is an on-screen guide for the user regarding the potential for tissue heating. The Mechanical Index (MI) is an on-screen guide with respect to the likelihood and magnitude of non-thermal effects. Users should remain aware of both indices while scanning, especially when changing scan modes, and should adjust the machine controls to keep them as low as reasonably achievable (ALARA principle) without compromising the diagnostic value of the examination [3]. Where low values cannot be achieved, examination times should be kept as short as possible [4].

\section{Adapt your Pre-sets}

The scanner pre-sets should be set so that the default power for a given examination is at the minimum level necessary. In obstetric applications, this default power should result in a TI no higher than 0.7 . The output should be increased during the examination only if this is necessary to produce a satisfactory diagnostic result. Some modes are more likely than others to produce significant acoustic outputs, and when these modes are used, particular care should be taken to regularly check the TI and MI Indices.

\section{Doppler mode}

Spectral pulse-wave Doppler and Doppler imaging modes (color flow imaging and power Doppler imaging), in particular, can produce more tissue heating and hence higher thermal indices, as can B-mode techniques involving coded transmissions. During scanning, the ALARA principle should be followed [5, 6].

\section{Elastography mode}

In general, a longer acoustical pulse sequence is needed in elastographic mode (but not in conventional strain imaging) than for Bmode imaging. Since the algorithms used to calculate TI for most imaging modes are not appropriate for elastography, it should be noted that the $\mathrm{TI}$ and $\mathrm{MI}$ displayed for these applications may represent an underestimate of the temperature rises and mechanical effects to be expected. In acoustic radiation force impulse (ARFI), the temperature has its maximum at the focus, and significant temperature rises may occur if bone lies in the beam. The scanning times should be kept short, especially when exposing vulnerable tissues [7].

\section{Harmonic imaging mode}

Tissue harmonic imaging mode can sometimes involve higher MI values. Users should be aware of the MI value displayed during scanning.

\section{$3 \mathrm{D} / 4 \mathrm{D}$ mode}

Three-dimensional imaging does not introduce any additional safety considerations, particularly if there are significant pauses during scanning to study or manipulate the reconstructed images. However, four-dimensional (real-time three-dimensional) scanning involves continuous exposure, and users should guard against the temptation to prolong examination times unduly in an effort to improve the recorded image sequence beyond that which is necessary for diagnostic purposes.

\section{Ultrasound Exposure During Pregnancy}

The embryo/fetus in early pregnancy is known to be particularly sensitive. In view of this and the fact that very little information is currently available regarding possible subtle biological effects of diagnostic levels of ultrasound on the developing human embryo or fetus, care should be taken to limit the exposure time and the $\mathrm{TI}$ and $\mathrm{MI}$ indices to the minimum commensurate with an acceptable clinical assessment, particularly when the $\mathrm{TI}$ exceeds 0.7 . In this case the exposure time has to be reduced and only TIs less than 3.0 are permitted.

Based on scientific evidence of ultrasound-induced biological effects to date, there is no reason to with-hold diagnostic scanning during pregnancy, provided it is medically indicated and is used prudently by fully trained operators. This includes routine scanning of pregnant women.

\section{Exposure of sensitive organs in the case of Doppler or Cardiotocography}

Temperature rises are likely to be greatest at bone surfaces and adjacent soft tissues. With increasing mineralization of fetal bones, the possibility of heating sensitive tissues such as brain, eye and spinal cord increases. The TI value has to be monitored during these scans and must be less than 1.0. The exposure time has to be reduced if the lung or intestine is scanned at MI values above 0.3 . Extra vigilance is advised when scanning such critical fetal structures at any stage in pregnancy and the ALARA principle should be applied.

However, Doppler ultrasound examinations should not be used routinely in the first trimester of pregnancy. The power levels used for fetal heart rate monitoring (cardiotocography - CTG) are sufficiently low, so that the use of this modality is not contraindicated on safety grounds, even when it is to be used for extended periods $[4,8]$. 


\section{Safety Considerations when Scanning Neonates or the Eye}

Particular care should be taken to reduce the risk of thermal and non-thermal effects during cardiac, pulmonal and cranial investigations of neonates. When scanning the neonatal brain, the TI should never exceed 3.0 and the duration of ultrasound exposure if $\mathrm{TI}$ is $>0.7$ should be restricted. However, there is experimental evidence that transducer self-heating can lead to a significant temperature rise at the skin surface, and so scanning times and exposure levels should be kept as low as possible [9].

In ophthalmic applications the TI could greatly underestimate the actual temperature rise in the eye because of the inappropriate underlying tissue model. Therefore, scanning has to be done with very low exposure levels compared to other diagnostic investigations. To reduce the risk of bioeffects, it is prudent to use $\mathrm{TI}<1$, and $\mathrm{MI}<0.23$ for eye scanning [10].

\section{Safety information concerning Ultrasound Contrast Agents}

These usually take the form of stable gas-filled microbubbles, which can potentially produce cavitation or microstreaming, the risk of which increases with the MI, scanning time and lower frequency. Data from small animal models suggest that microvascular damage or rupture is possible. Caution should be considered for the use of ultrasound contrast agents in tissues where damage to the microvasculature could have serious clinical implications, such as the brain and the eye [10-12]. As in all diagnostic ultrasound procedures, the MI and TI should be continually checked and kept as low as possible.

It is possible to induce premature ventricular contractions in contrast-enhanced echocardiography when using high MI values and end-systolic triggering. Users should take appropriate precautions in these circumstances.

The use of contrast agents is still off-label in pregnancy, renal assessment and in intravenous application in pediatric patients. Specifically for the assessment of focal liver lesions in pediatrics, the application of a contrast agent has been approved [13, 14].

Intravenous and intracavity application of ultrasound contrast agents should be avoided 24 hours prior to extra-corporeal shock wave therapy $[15,16]$. Since a rare allergic response to these agents has been seen $(1: 10000,[14])$, it is recommended that an "allergy kit" be readily available at all times during these procedures.

Current safety statements are available on EFSUMB's website, while only a few have been published in Ultraschall in der Medizin/ European Journal of Ultrasound or in the EFSUMB Newsletter [17, 18].

\section{Conflict of Interest}

The authors declare that they have no conflict of interest.
References

[1] Miller DL, Dong Z, Dou C et al. Pulmonary Capillary Hemorrhage Induced by Different Imaging Modes of Diagnostic Ultrasound. Ultrasound Med Biol 2018; 44: 1012-1021. doi:10.1016/j.ultrasmedbio.2017.11.00

[2] Ang ES Jr, Gluncic V, Duque A et al. Prenatal exposure to ultrasound waves impacts neuronal migration in mice. Proc Natl Acad Sci USA 2006; 103: 12903-12910. doi:10.1073/pnas.0605294103

[3] Sande RK, Matre K, Eide GE et al. Ultrasound safety in early pregnancy: reduced energy setting does not compromise obstetric Doppler measurements. Ultrasound Obstet Gynecol 2012; 39: 438-443. doi:10.1002 uog. 10148

[4] ECMUS. Thermal (TI) and Mechanical (MI) Indices. Tutorial (2011). http://www.efsumb.org/safety/resources/thermal_mechanical_indice s_explanation.pdf

[5] ECMUS. Doppler ultrasound devises - safety aspects. Tutorial (2011). http://www.efsumb.org/safety/resources/doppler_ultrasound_safety_ aspects_2011update.pdf

[6] ECMUS. Best practice guidance for the safe use of Doppler ultrasound (2019). http://www.efsumb.org/blog/wp-content/uploads/2019/06/ 2019-doppler_bestpractice.pdf

[7] ECMUS. Elastography - safety aspects. Tutorial (2014). http://www. efsumb.org/safety/resources/elastography_safety_aspects.pdf

[8] ECMUS. Statement on the safe use of Doppler Ultrasound during scans at 11-14 weeks (or earlier in pregnancy). Consensus Statement (update 2019). http://www.efsumb.org/blog/wp-content/uploads/2019/06/ 2019-first_trimester_doppler_statement-1.pdf

[9] ECMUS. Neonatal cranial ultrasound - safety aspects. Tutorial (2013). http://www.efsumb.org/safety/resources/neonatal_cranial_ultrasound_ safety_aspects.pdf

[10] Harris GR. Safety Considerations for Diagnostic Ultrasound in the Eye. J Ultrasound Med 2019; 38: 1163-1165. doi:10.1002/jum.14977

[11] Miller DL, Averkiou MA, Brayman AA et al. Bioeffects considerations for diagnostic ultrasound contrast agents. J Ultrasound Med 2008; 27: 611-632. doi:10.7863/jum.2008.27.4.611

[12] Hynynen K, McDannold N, Martin $\mathrm{H}$ et al. The threshold for brain damage in rabbits induced by bursts of ultrasound in the presence of an ultrasound contrast agent (Optison $®)$. Ultrasound in Med \& Biol 2003; 29: 473-481. doi:10.1016/S0301-5629(02)00741-X

[13] Sidhu PS, Cantisani V, Daganello A et al. Role of Contrast-Enhanced Ultrasound (CEUS) in Paediatric Practice: An EFSUMB Position Statement. Ultraschall in Med 2017; 38: 33-43. doi:10.1055/s-0042-110394

[14] Sidhu PS, Cantisani V, Dietrich CF et al. The EFSUMB Guidelines and Recommendations for the Clinical Practice of Contrast-Enhanced Ultrasound (CEUS) in Non-Hepatic Applications: Update 2017 (Long Version). Ultraschall in Med 2018; 39: e2-e44. doi:10.1055/a-0586-1107

[15] Albrecht T, Leen E, Blomley $M$ et al. Guidelines for the use of contrast agents in Ultrasound (January 2004). Ultraschall in Med 2004; 25: 249-256. doi:10.1055/s-2004-813245

[16] Mornstein V. Cavitation-induced risks associated with contrast agents used in ultrasonography. European Journal of Ultrasound 1997; 5: 101-111

[17] Rott HD. EFSUMB statement on the clinical safety of ultrasound diagnostis. Ultraschall in Med 1996; 17: 257-258

[18] EFSUMB. Clinical safety statement for diagnsotic ultrasound - 2008. EFSUMB Newsletter issue 5. Ultraschall in Med 2008; 29: 552. doi:10.1055/s-0028-1098034 